\title{
EDUCANET: novos espaços de interação
}

\author{
Patrícia B. Scherer Bassani ${ }^{1}$, Elias Wallauer ${ }^{2}$, Lovani Volmer ${ }^{2}$, Cristina Ennes da \\ Silva ${ }^{3}$ \\ ${ }^{1}$ Universidade Feevale - Rodovia RS-239, 2755 \\ Novo Hamburgo - RS - Brasil \\ ${ }^{2}$ Escola de Educação Básica - Escola de Aplicação Feevale \\ Novo Hamburgo - RS - Brasil \\ \{patriciab, eliasw, lovaniv, crisennes\} @feevale.br
}

\begin{abstract}
This article presents the Educanet project, developed within the School of Basic Education - School Application Feevale. The project aims to create different spaces of interaction to enhance educational practices with the use of information and communication technologies. The project is based on two actions: connected room (digital blackboard) and tablets in education. Results indicate that the availability of diverse technologies, together with a teacher formation process based on practice, provides opportunities to different pedagogical practices that drive to more interaction and student participation.
\end{abstract}

Resumo. Este artigo apresenta o projeto Educanet, desenvolvido no âmbito da Escola de Educação Básica - Escola de Aplicação Feevale. O projeto tem por objetivo oportunizar diferentes espaços de interação para impulsionar práticas educativas inovadoras com o uso das tecnologias da informação $e$ comunicação. $O$ projeto se constitui a partir de duas ações: Sala conectada e tablets na educação. Resultados apontam que a disponibilização de tecnologias diversificadas, aliadas a um processo de formação de professores centrado na prática, oportuniza diferentes práticas pedagógicas, que impulsionam maior interação e participação dos alunos.

\section{Introdução}

Este artigo apresenta o projeto Educanet, desenvolvido no âmbito da Escola de Educação Básica - Escola de Aplicação Feevale.

A escola tem como missão "oportunizar ao educando a construção do conhecimento, proporcionando a continuidade e a conclusão da educação básica, a partir de um ensino inovador, tendo a pesquisa como princípio educativo, respeitando os tempos de aprendizagem dos sujeitos, visando à formação de cidadãos éticos e críticos".

A partir de uma concepção sociointeracionista, a Escola de Educação Básica Feevale - Escola de Aplicação compreende a educação como construção coletiva permanente, baseada nos princípios de convivência, solidariedade, justiça, respeito, valorização da vida na diversidade e na busca do conhecimento. Nessa perspectiva, 
utiliza-se de uma metodologia cooperativa e participativa, que contribua na construção da autonomia.

A proposta pedagógica da escola compreende o uso das tecnologias da informação e comunicação (TIC) de forma integrada às atividades curriculares, baseada em uma perspectiva que busca articular $\mathrm{o}$ trabalho docente às atividades de aprendizagem realizadas em laboratório de informática.

Destaca-se, também, que a Escola de Aplicação entende a pesquisa como princípio educativo e como espaço de produção de conhecimento acadêmico-científico na área de educação, por meio de uma relação dialética com os cursos da Universidade Feevale.

Nessa perspectiva, a partir da experiência da Escola de Aplicação na área de Informática na Educação e com o objetivo de ampliar suas ações no uso das tecnologias da informação e comunicação no contexto educativo e, por outro lado, impulsionada pelos estudos recentes na área de Informática na Educação, o ano de 2011 marca o início do projeto Educanet: novos espaços de interação.

Este artigo está assim organizado: parte-se de uma apresentação do projeto e fundamentação teórica, na seção 2; na seção 3 está apresentada a metodologia de trabalho; na seção 4 apresentação os resultados, seguido das considerações finais, na seção 5 .

\section{O projeto Educanet}

O projeto Educanet ${ }^{1}$ tem por objetivo oportunizar diferentes espaços de interação para impulsionar práticas educativas inovadoras com o uso das tecnologias da informação e comunicação. Este projeto, que "nasce" na Escola de Aplicação, se efetiva por meio da parceria com a graduação, especialmente com os cursos de Computação, e na pós-graduação, com o Programa de Pós-Graduação em Diversidade Cultural e Inclusão Social, especialmente com as pesquisas vinculadas ao Grupo de Pesquisa em Informática na Educação.

Estudos atuais na área de Informática na Educação apontam que existem três conceitos que se repetem na literatura e que apontam para um horizonte bastante provável: adaptação, cooperação e mobilidade (COLL e MONEREO, 2010). Assim, este projeto busca referência nestes três pilares para organizar sua proposta.

O conceito de adaptação refere-se ao desenvolvimento de interfaces de software que sejam capazes de se adaptar (de forma automática ou não) ao perfil do sujeito. A Escola de Aplicação caracteriza-se como uma escola inclusiva e, assim, a seleção de ambientes computacionais e softwares para uso no projeto deve levar em conta os recursos de acessibilidade e usabilidade, possibilitando o acesso e utilização pelos diferentes alunos.

O conceito de cooperação é entendido a partir de uma concepção construtivistainteracionista, embasada na perspectiva Piagetiana. Piaget (1973) aponta que as trocas interindividuais baseadas em cooperação representam o mais alto nível de socialização e

\footnotetext{
1 Este projeto foi contemplado no $3^{\circ}$ Prêmio Sinepe de Inovação em Educação - Sindicato dos Estabelecimentos do Ensino Privado no Estado do Rio Grande do Sul - categoria Bronze - área fim.
} 
as relações de cooperação envolvem discussão e troca de pontos de vista e implicam igualdade de direito ou autonomia.

Entende-se que pensar a educação no ciberespaço tende a (re)colocar em pauta as ideias de aprendizagem colaborativa. O ciberespaço (ou "rede") é o novo meio de comunicação que surge da interconexão mundial dos computadores. Conforme Levy (2001) chama-se de cibercultura ao conjunto de técnicas (materiais e intelectuais), de práticas, de atitudes, de modos de pensamento e de valores que se desenvolvem junto com o crescimento do ciberespaço. Estudos atuais apontam que o ciberespaço suporta tecnologias intelectuais que amplificam, exteriorizam e modificam numerosas funções cognitivas, como a memória, a imaginação, a percepção e o raciocínio (LEVY, 2001, ALAVA, 2002). Essas "tecnologias intelectuais" favorecem novas formas de acesso à informação, além de novos estilos de raciocínio e conhecimento. Além disso, por meio do ciberespaço, estas tecnologias podem ser compartilhadas.

Sistemas compartilhados na web, essencialmente caracterizados pela possibilidade de participação e intervenção dos sujeitos, possibilitando a interação de muitos-para-muitos, constituem a base do conceito de web 2.0. Conforme O'Reilly (2007), a web 2.0 é a rede como plataforma, abarcando todos os dispositivos conectados a ela. As aplicações web 2.0 são aquelas que utilizam as possibilidades desta plataforma criando efeitos na rede através de uma arquitetura de participação. Chama-se este tipo de aplicação de software social. Conforme Spyer (2007, p. 21), "o termo social software é usado para se referir ao tipo de programa que produz ambientes de socialização pela internet, ele é que está por trás da colaboração online", como redes de relacionamento (Orkut, Facebook), blogs, micro-blogs (Twitter), wikis, compartilhamento de arquivos e outros.

Do ponto de vista da educação, o ciberespaço não pode ser reduzido a um espaço tecnológico que permite assegurar melhor a transmissão passiva do saber, mas deve ser entendido como um espaço social de comunicação e de trabalho em grupo (ALAVA, 2002). Pisani e Piotet (2010) apontam que os atuais usuários da web não são mais navegadores passivos, que apenas consomem o conteúdo disponibilizado por especialistas. Para eles, os usuários atuais "propõem serviços, trocam informações, comentam, envolvem-se, participam" (p.16). Esses novos usuários, que não se contentam em apenas navegar, mas produzem conteúdo na web, são chamados de web atores.

Torna-se relevante destacar, também, que a ubiquidade das tecnologias da informação e comunicação (TIC) multiplica as possibilidades e os contextos de aprendizagem para além da sala de aula presencial (COLL, ILLERA, 2010). O crescente uso das redes sem fio e de dispositivos móveis (tablets, smarthphones, notebooks, etc.) vêm concretizando o paradigma computacional da Computação Móvel e Ubíqua, permitindo o acesso a serviços e dados independente da localização física dos sujeitos, tendo como suporte as tecnologias de rede sem fio e sistemas distribuídos. Assim, o uso de sistemas compartilhados na web através de tecnologias móveis amplia as possibilidades de ensinar e aprender para além do espaço formal da sala de aula, oportunizando um espaço constante de trocas entre alunos e professores. O conceito de mobilidade remete a essa possibilidade de expandir as opções de aprendizado para diferentes cenários. 
Portanto, entende-se que a ubiquidade das tecnologias da informação e comunicação na educação e a arquitetura de participação da web 2.0 oportunizam diferentes possibilidades de ensinar e aprender.

O projeto Educanet se constitui a partir de duas ações:

a) Sala conectada;

b) Tablets na educação.

A Sala Conectada caracteriza-se como um espaço onde professores e alunos podem experienciar diferentes possibilidades de ensinar e aprender, por meio do uso de diferentes tecnologias, enfatizando a interação e a interatividade. Este laboratório, disponível desde 2011, é composto por 32 netbooks, 1 lousa digital interativa, 1 projetor, 1 prancheta interativa do professor, 1 prancheta interativa de aluno, 1 câmera de documentos, 32 teclados de votação e um software para gerenciamento das atividades.

A utilização dos tablets na educação iniciou em 2012, quando a escola adquiriu 20 iPads, que atualmente são utilizados apenas na educação infantil e nos anos iniciais do ensino fundamental.

\subsection{Objetivos e desafios}

O projeto Educanet tem como objetivo oportunizar diferentes espaços de interação para impulsionar práticas educativas inovadoras com o uso das tecnologias da informação e comunicação.

Como objetivos específicos, destacam-se:

- oportunizar aos professores experiências no uso de diferentes tecnologias da informação e comunicação no contexto educativo;

- selecionar aplicativos para dispositivos móveis que possam ser utilizados em projetos educativos;

- selecionar e analisar ferramentas web com potencial para uso na sala de aula.

Os desafios encontrados no projeto são:

a) desenvolvimento de aplicativos para uso nos tablets: existem vários aplicativos interessantes disponíveis de forma gratuita para uso nos iPads. Entretanto, percebe-se que ainda faltam opções em língua portuguesa. Dessa forma, um dos desafios consiste na parceria entre a Escola de Aplicação e o projeto GetMove, vinculado ao curso de Computação da Universidade Feevale, para o desenvolvimento de aplicativos específicos;

b) formação de professores para uso de ferramentas web: a formação dos professores para uso da Sala Conectada focou, em um primeiro momento, a apropriação tecnológica de hardware e software e a discussão das possibilidades de uso na sala de aula. Entretanto, percebe-se que para utilizar o potencial de comunicação e interação das ferramentas web 2.0 será necessário oportunizar aos professores cursos de formação específicos (oficinas);

c) divulgação interna dos resultados de pesquisa: vários trabalhos interessantes estão sendo desenvolvidos tanto com os tablets como na Sala Conectada e se percebe a 
necessidade de criar espaços para a troca de experiências entre os professores. Entendese que compartilhar os trabalhos/projetos desenvolvidos nas diferentes turmas pode também impulsionar novas práticas.

\section{Metodologia}

O projeto envolve professores e alunos da Escola de Aplicação, conforme a sua especificidade:

a) Sala conectada: educação básica e ensino médio;

b) Tablets: educação infantil e anos iniciais do ensino fundamental.

Inicialmente foi realizado um processo de formação dos professores para uso da Sala Conectada, que envolveu tanto aspectos tecnológicos quanto aspectos pedagógicos do uso de novas tecnologias na educação. Todos dos professores que realizaram a formação estão habilitados a utilizar a Sala Conectada. Do total de professores da escola (48), 38 fizeram o curso.

A formação para uso dos tablets aconteceu de forma diferenciada. Todos os professores envolvidos no projeto foram acompanhados de forma individual e/ou em pequenos grupos para estudos sobre o uso dos tablets na sala de aula. No total são 6 professores.

A metodologia proposta para o projeto segue as orientações do documento Padrões de Competência em TIC para Professores, desenvolvido pela UNESCO (2009), que tem por objetivo apresentar diretrizes que possam orientar e impulsionar novas práticas educativas combinando habilidades em TIC com inovações em pedagogia, currículo e organização escolar. Dessa forma, entende-se que a efetiva utilização das TIC no contexto educativo perpassa pelo processo de formação dos professores.

A proposta da UNESCO (2009), embasada nos quatro pilares da aprendizagem (aprender a conviver, aprender a saber, aprender a fazer, aprender a ser), compreende a aprendizagem como um processo contínuo ao longo da vida, delineia novas metas de aprendizagem e participação em uma sociedade de aprendizagem, com base na construção e compartilhamento de conhecimento. A proposta contempla três abordagens complementares.

A primeira envolve a alfabetização digital do professor, para que ele possa integrar o uso das TIC ao currículo escolar padrão, à pedagogia e às estruturas de sala de aula. Entende-se que os professores devem saber como, onde e quando usar (ou não usar) a tecnologia para as atividades educativas em sala de aula, atividades de gestão ou para formação profissional do próprio docente.

Na Escola de Aplicação, conforme dito anteriormente, o uso do computador na educação já é uma realidade, mas as atividades são centralizadas em laboratório de informática. Percebe-se o desafio de oportunizar aos professores o conhecimento e a experiência em novos espaços de interação, que possam oportunizar diferentes práticas educativas com o uso das TIC. Portanto, este processo de alfabetização digital envolve um movimento de (re)aprender novas possibilidades de uso do computador sob a perspectiva da aprendizagem colaborativa em diferentes espaços físicos e digitais (ciberespaço). 
A segunda abordagem envolve o aprofundamento do conhecimento. Estas mudanças devem ser amplas e ter mais impacto sobre a aprendizagem, oportunizando habilidades para experienciar e utilizar metodologias e tecnologias mais sofisticadas, impulsionando mudanças no currículo.

A terceira e mais complexa das abordagens é a de criação de conhecimento, uma vez que nessa modalidade o "currículo ultrapassa as fronteiras das disciplinas escolares, com a inclusão das habilidades provenientes das demandas do século XXI em direção a um novo conhecimento que envolve o aprendizado por toda a vida - a habilidade de colaborar, comunicar, criar, inovar e pensar de forma crítica" (UNESCO, 2009, p. 11).

Assim, entende-se que a efetiva utilização das TIC no contexto educativo perpassa por um processo de formação docente que envolve tanto a apropriação individual das diferentes ferramentas de interação e comunicação quanto a vivência na/em rede, de forma a compreender o processo de aprendizagem coletiva.

\subsection{Estratégias}

As tabelas 1 e 2 apresentam as estratégias de desenvolvimento das atividades na Sala Conectada e sobre os tablets na sala de aula.

Tabela 1 - Sala Conectada

\begin{tabular}{|c|c|c|}
\hline Semestre & Atividade & Detalhamento \\
\hline \multirow{4}{*}{$2011 / 01$} & Acompanhamento das instalações da Sala Conectada & Atividade realizada pela equipe gestora \\
\hline & $\begin{array}{l}\text { Apropriação tecnológica } \text { dos } \\
\text { Conectada }\end{array}$ & $\begin{array}{l}\text { Formação para a equipe gestora e } \\
\text { funcionários da equipe de suporte de } \\
\text { informática }\end{array}$ \\
\hline & Planejamento dos cursos & Atividade realizada pela equipe gestora \\
\hline & Inauguração da Sala Conectada & Público interno e externo. \\
\hline \multirow{3}{*}{$2011 / 02$} & $\begin{array}{l}\text { Formação de professores - etapa } 1 \text { (alfabetização } \\
\text { digital) }\end{array}$ & $\begin{array}{l}\text { Cursos de formação para a apropriação } \\
\text { tecnológica dos equipamentos da Sala } \\
\text { Conectada (hardware e software) e } \\
\text { reflexão sobre o potencial de uso nos } \\
\text { processos de ensino-aprendizagem }\end{array}$ \\
\hline & Primeiras experiências na Sala Conectada & $\begin{array}{l}\text { Acompanhamento dos professores no uso } \\
\text { da sala; apresentação aos alunos }\end{array}$ \\
\hline & Compartilhando experiências com a comunidade & $\begin{array}{l}\text { Participação em eventos } \\
\text { Mostra das Profissões- } \\
\text { acompanhamentratec e e de } \\
\text { interessados em conhecer o ambiente e a } \\
\text { proposta. }\end{array}$ \\
\hline $2012 / 01$ & $\begin{array}{l}\text { Formação de professores - etapa } 1 \text { (alfabetização } \\
\text { digital) }\end{array}$ & $\begin{array}{l}\text { Novos cursos de formação para a } \\
\text { apropriação } \\
\text { equipamentos decnológica da Sala Conectada } \\
\text { (hardware e software) e reflexão sobre o } \\
\text { potencial de uso nos processos de ensino- } \\
\text { aprendizagem }\end{array}$ \\
\hline \multirow[b]{2}{*}{$2012 / 02$} & $\begin{array}{l}\text { Formação de professores - etapa } 2 \text { (aprofundamento } \\
\text { do conhecimento) }\end{array}$ & $\begin{array}{l}\text { Acompanhamento aos professores no uso } \\
\text { do ambiente. Vários professores iniciaram } \\
\text { processo de utilização da Sala Conectada } \\
\text { de forma independente. }\end{array}$ \\
\hline & $\begin{array}{l}\text { Estudo de diferentes ferramentas de comunicação e } \\
\text { interação na web, para ampliar o potencial do uso da } \\
\text { lousa digital }\end{array}$ & $\begin{array}{l}\text { Atividade realizada em parceria com o } \\
\text { Grupo de Pesquisa em Informática na } \\
\text { Educação. A proposta é disponibilizar um } \\
\text { e-book (2013) sobre "ferramentas web } \\
2.0 \text { na educação" }\end{array}$ \\
\hline
\end{tabular}


Tabela 2 - Tablets na sala de aula

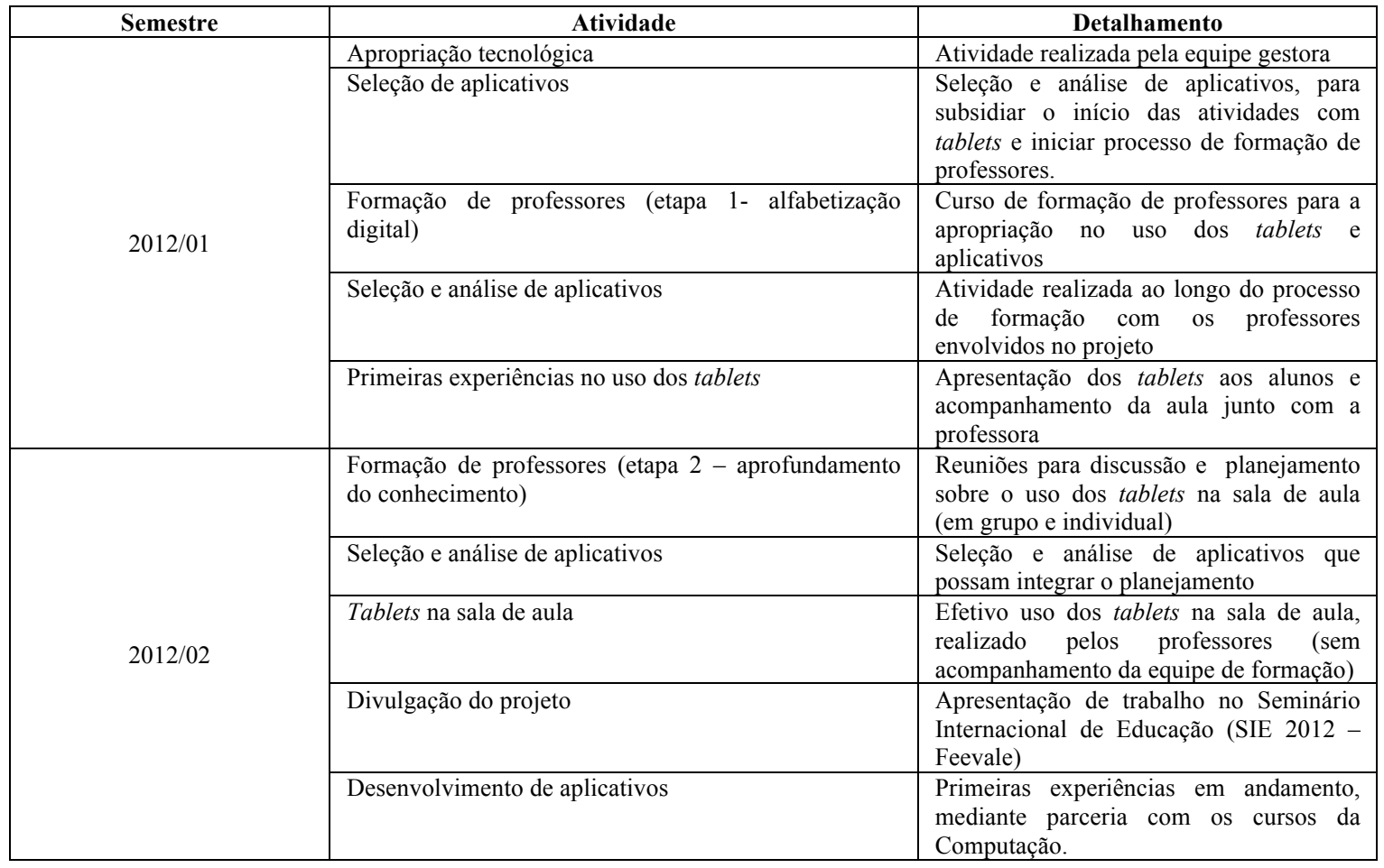

\subsection{Recursos}

Para a realização deste projeto os seguintes recursos foram utilizados:

a) Recursos materiais:

- Sala Conectada: 32 netbooks, 1 lousa digital interativa (utiliza o software Interwrite Worksapce), 1 projetor, 1 prancheta interativa do professor, 1 prancheta interativa de aluno, 1 câmera de documentos, 32 teclados de votação e um software para gerenciamento das atividades (Lanschool);

- Tablets: 20 iPads.

b) Recursos humanos:

- 20h de atividades semanais, divididas em dois professores responsáveis pelo processo de formação.

c) Recursos financeiros: o projeto tem apoio financeiro da Feevale.

\section{Resultados alcançados}

Considerando os aspectos quantitativos, tem-se os seguintes resultados:

a) Sala Conectada: do total de 48 professores da Escola de Aplicação, 38 fizeram o curso. Destes, percebe-se um uso efetivo dos professores das disciplinas de Inglês, História, Literatura, dos professores dos cursos técnicos em Informática e Publicidade, além dos professores do currículo, especialmente a turma de $4^{\circ}$ ano. 
b) Tablets na sala de aula: todos os professores da educação infantil e anos iniciais do ensino fundamental participaram do processo de formação e estão utilizando os iPads na sala de aula.

Em relação aos aspectos qualitativos, documenta-se o envolvimento de professores e alunos com a proposta, a partir do relato de algumas atividades realizadas.

O uso da Sala Conectada com a turma do $4^{\circ}$ ano ( $2^{\mathrm{a}}$ etapa $-2^{\circ}$ ciclo) envolveu um primeiro momento de apropriação da lousa pelos alunos. Depois, foram realizadas atividades como:

- exercício de tabuada com o uso dos votadores (questões de múltipla escolha foram disponibilizadas e os alunos escolhem as respostas por meio de equipamentos votadores - e os resultados aparecem no quadro em forma de gráfico, mostrando número de acertos e erros). Esta proposta foi interessante, pois oportunizou uma forma divertida de refletir sobre a apropriação da tabuada;

- texto coletivo, elaborado em pequenos grupos nos netbooks e depois finalizado de forma coletiva utilizando os recursos da lousa digital.

$\mathrm{Na}$ disciplina de História os alunos foram desafiados a elaborarem um texto coletivo no GoogleDocs, a partir de pesquisa online de dados no site do Museu Imperial. A dinâmica do trabalho envolveu navegação compartilhada, a partir dos recursos da lousa digital, e construção coletiva.

A Sala Conectada também oportunizou dinâmicas diferenciadas nas aulas de Inglês, principalmente com as etapas iniciais do ensino fundamental. Os alunos participam diretamente na realização de atividades e correções na lousa.

A leitura poética também foi exercitada na Sala Conectada, por meio de atividades propostas articulando atividades individuais de produção nos notebooks e discussão coletiva a partir de diferentes usos da lousa.

A Sala Conectada também está sendo utilizada pelas turmas dos cursos técnicos em Informática e em Publicidade.

Os trabalhos com o uso do iPad na sala de aula iniciaram com a presença dos professores da equipe de formação, para conversar com os alunos, especialmente sobre os cuidados com o equipamento. As primeiras experiências no uso dos iPads foram de uso de livre, para que os alunos pudessem explorar o equipamento. $\mathrm{O}$ uso dos iPads entusiasmou alunos e professores, conforme mostram os depoimentos.

a) professora da $1^{\mathrm{a}}$ Etapa do $1^{\circ}$ Ciclo do Ensino Fundamental $\left(1^{\circ}\right.$ ano):

O uso de iPads na sala de aula está trazendo muitas contribuições para o processo de alfabetização dos alunos da $1^{\mathrm{a}}$ Etapa do $1^{\circ}$ Ciclo do Ensino Fundamental. Os aplicativos oferecem a possibilidade de construir conhecimentos de uma maneira lúdica e divertida, além de proporcionarem a cooperação entre as crianças durante a exploração dessa nova tecnologia.

b) professora da $2^{\mathrm{a}}$ Etapa do $1^{\circ}$ Ciclo do Ensino Fundamental ( $2^{\circ}$ ano):

Particularmente, percebi o quanto esse desafio é recheado de ingredientes que levam ao sucesso: fazer uso dos diversos aplicativos em sala de aula com os alunos me fez perceber que faço muitas coisas "iguais ao que se faz todo dia, mas de um jeito diferente". Esse jeito diferente é que faz a diferença: alunos entusiasmados, mostrando habilidades que antes eram tão difíceis de serem trabalhadas, tais como: procurar uma informação, compartilhá-la, ampliá-la, isto é, buscar a informação com mais 
II Congresso Brasileiro de Informática na Educação (CBIE 2013)

Workshops (WCBIE 2013)

profundidade e qualidade, e tudo isso em menos tempo. E assim, nossos alunos, vivem agora num tempo e num espaço compatíveis com sua velocidade e sede de aprender.

Aponto também, outros aspectos que considero importantes no uso de iads em sala de aula:

- a mobilidade: poder estar em grupos, sentados em roda, no chão, no pátio, não sendo necessário mais o uso e o deslocamento constante até o Laboratório de Informática;

- facilidade de realizar os registros, mesmo de alunos em etapas de alfabetização, usando para isso, aplicativos adequados;

- possibilidade de planejamento e construção das aulas, de acordo com o ritmo de cada grupo de alunos;

- utilização para atividades lúdicas e jogos pedagógicos;

- o contato visual entre os alunos e entre o professor e o aluno é mais amplo, se comparado com o Laboratório de Informática.

Enfim, penso que o uso de iPads na sala de aula, independente de faixa etária, traz inúmeros benefícios, tanto para educadores quanto para alunos, entre eles destaco principalmente a aproximação do mundo real ao mundo escolar. Assim, a escola passa a ter um novo significado dentro de um panorama que se revela mundialmente.

c) professor da turma 012BT - Educação Infantil (turno: tarde)

O iPad foi uma novidade que chegou em nossa escola neste ano com o objetivo de integrar novas tecnologias às atividades curriculares, possibilitando através dos aplicativos educativos diferentes fontes de pesquisa, descoberta e aprendizagem. Os educandos demonstraram muito interesse e exploram o tablet com facilidade, descobrindo novas ferramentas, pesquisando, desenhando, escrevendo palavras, explorando o planeta Terra, montando quebra-cabeças e muitas outras intervenções que são descobertas a cada semana.

O Aplicativo Google Earth foi muito explorado pelos educandos durante o projeto "Mistérios da Noite": Estávamos no espaço e fomos nos aproximando da Terra, percebemos que ela aumentava e se movimentava ao toque mágico do nosso dedo. Quanto mais nos aproximávamos, maior ficava nosso Planeta Terra. E agora, o que fazer? Os olhos brilhavam, a ansiedade se misturava com o medo e eis que alguém grita - "Não ficamos dentro da terra e sim fora dela". Localizamos nossa escola e, a partir desse momento fomos pesquisar, porque não "caímos da terra" se estamos "fora dela"?

Desta forma, outros aplicativos são explorados pelos educandos em diferentes momentos, sendo que em cada intervenção novos objetivos são alcançados. Alguns educandos demonstraram interesse pelas letras do alfabeto no momento que explorávamos o Aplicativo ABC do Bita. Quando descobrem um caminho novo, uma maneira diferente de fazer partilham com os colegas e trocam saberes. O uso do iPad, nas aulas da Educação Infantil, está sempre relacionado com o assunto que estamos pesquisando.

A cada planejamento os iPads se integram com as atividades curriculares, onde desenvolvemos habilidades e atingimos todas as linguagens e áreas do conhecimento. É uma nova forma de aprendizagem que vem somar à outras já realizadas e os aplicativos selecionadas previamente, facilitam a aprendizagem dos educandos. Os iPads possibilitam ao ensino uma expansão de opções, que enriquecem o trabalho na sala de aula. Como educadora, procuro estar sempre lendo e pesquisando, pois também foi uma novidade e uma ferramenta a mais na minha prática diária.

\section{Considerações finais}

A partir da experiência documentada neste projeto entende-se que os novos espaços de interação estão oportunizando práticas educativas inovadoras com o uso das tecnologias da informação e comunicação, tanto na Sala Conectada quanto no uso dos iPads na sala de aula.

Importante destacar que o processo de formação de professores realizado com base na proposta da Unesco (2009) mostrou-se um importante balizador das atividades propostas. O processo de formação, que teve início com a alfabetização digital dos 
professores encontra-se atualmente na fase de aprofundamento do conhecimento, onde as novas práticas estão sendo integradas de forma articulada aos diferentes currículos.

Novas atividades estão em andamento na escola, especialmente no uso de tablets. Nos anos iniciais do ensino fundamental, busca-se superar a ênfase nos aplicativos e oportunizar atividades efetivamente integradas aos conteúdos e ao dia-adia dos alunos.

Nos anos finais do ensino fundamental, está em desenvolvimento o projeto "Ensinar e aprender em/na rede: a arquitetura de participação da web 2.0 no contexto da educação presencial". Este projeto, contemplado no edital MCTI/CNPq/MEC/CAPES No 18/2012, envolve a utilização de ferramentas da web 2.0 por meio de dispositivos móveis do tipo tablets, sob a perspectiva da aprendizagem colaborativa. O público-alvo da pesquisa são professores e alunos dos anos finais do ensino fundamental da Escola de Aplicação Feevale (http://ensinareaprenderemrede.wordpress.com).

Entretanto, percebe-se que ainda são vários os desafios, a fim de consolidar a prática docente em novos espaços de interação, especialmente o tempo destinado para a formação dos professores e o seu envolvimento no processo de seleção e análise de aplicativos.

\section{Referências}

Alava, S (2002) “Ciberespaço e formações abertas”. Porto Alegre: Artes Médicas.

Coll, C. and Monereo, C. (2010) "Educação e aprendizagem no século XXI", In: Psicologia da Educação Virtual, Edited by Cesar Coll and Carles Monereo, Artmed, Porto Alegre.

Coll, C. and Illera, J. L.R. (2010) “Alfabetização, novas alfabetizações e alfabetização digital: as TIC no currículo escolar”, In: Psicologia da Educação Virtual, Edited by Cesar Coll and Carles Monereo, Artmed, Porto Alegre.

Lévy, P. (2001) “A Conexão Planetária”. São Paulo: Editora 34, 2001.

O'reilly, T. (2007) "What is web 2.0”, Communications and Strategies, n 65.

Piaget, J. (1973) “Estudos Sociológicos”, Rio de Janeiro: Forense.

Pisani, F. and Piotet, D. (2010) “Como a web transforma o mundo”, São Paulo: Senac.

Spyer, J. (2007) “Conectado”, Rio de Janeiro: Jorge Zahar.

TIC EDUCAÇÃO 2010. Pesquisa sobre o uso das tecnologias de informação e comunicação no Brasil. São Paulo: Comitê Gestor da Internet no Brasil, 2011.

UNESCO. Padrões de Competência em TIC para Professores. 2009. 